\title{
Arginase inhibition protects against hypoxia-induced pulmonary arterial hypertension
}

\author{
WENJIN JIANG ${ }^{*}$, BOLIN SUN*, XUEPENG SONG, YANBO ZHENG, LIGANG WANG, \\ TAO WANG and SHENG LIU
}

Department of Interventional Radiology, Yantai Yuhuangding Hospital, Yantai, Shandong 264000, P.R. China

Received August 30, 2014; Accepted May 19, 2015

DOI: $10.3892 / \mathrm{mmr} .2015 .3994$

\begin{abstract}
The present study aimed to determine the role of arginase (Arg) in pulmonary arterial hypertension (PAH). In vitro, human pulmonary artery smooth muscle cells (HPASMCs) were cultured under hypoxic conditions with, or without, the Arg inhibitor, S-(2-boronoethyl)-L-cysteine (BEC), for $48 \mathrm{~h}$, following which the proliferation of the HPASMCs was determined using MTT and cell counting assays. For the in vivo investigation, 30 male rats were randomly divided into the following three groups $(n=10$ per group): i) control group, ii) PAH group and iii) BEC group, in which the right ventricle systolic pressure (RVSP) of the rats was assessed. The levels of cyclin D1, cyclin-dependent kinase (CDK) 4 and p27 were measured in vitro and in vivo. The phosphorylation levels of Akt and extracellular-related kinase (ERK) were also measured in HPASMCs. In vitro, compared with the hypoxia group, Arg inhibition reduced HPASMC proliferation and reduced the expression levels of cyclin D1, CDK4, phosphorylated (p-)Akt and p-ERK. By contrast, Arg inhibition increased the expression of $\mathrm{p} 27$. In vivo, compared with the control group, the expression levels of cyclin D1 and CDK4 were reduced in the PAH group, however, the expression of p27 and the RVSP increased. In the BEC group, the opposite effects were observed. Therefore, it was suggested that Arg inhibition may reduce the RVSP of PAH rats and reduce HPASMC proliferation by decreasing the expression levels of cyclin D1 and CDK4, increasing the expression of p27, and partly reducing the phosphorylation of Akt and ERK.
\end{abstract}

Correspondence to: Dr Xuepeng Song, Department of Interventional Radiology, Yantai Yuhuangding Hospital, 20 Yuhuangding East Road, Yantai, Shandong 264000, P.R. China

E-mail: songxuepengyhd@163.com

*Contributed equally

Key words: arginase, hypoxia, pulmonary arterial hypertension, proliferation, human pulmonary artery smooth muscle cells

\section{Introduction}

Pulmonary arterial hypertension (PAH) is a life-threatening disease, which contributes to the morbidity and mortality rates of patients with various lung and heart diseases (1). PAH has a multifactorial pathology; and a variety of cell types, including endothelial cells, smooth muscle cells, inflammatory cells and platelets, may be implicated in the progression of PAH (2).

Vascular smooth muscle cells (VSMCs) are present in the medial wall of blood vessels, which are normally quiescent and express a differentiated phenotype to maintain vascular tone. However, under pathological conditions, VSMCs switch to a 'synthetic' phenotype, secrete inflammatory cytokines and contribute to vascular pathogenesis (3). VSMC proliferation of the pulmonary artery has been considered as one of the major causes of pulmonary arterial remodeling (4). Progressive pulmonary arterial remodeling is a characteristic of PAH, which is central to the persistent deterioration and the irreversibility of the disease (5). At present, few therapeutic options are effective for targeting pulmonary arterial structure remodeling following development of PAH.

Nitric oxide (NO), one of the smallest known bioactive products in mammalian cells, has an important role in controlling vascular tone and structure, in which it mediates relaxation of the vessels through the activation of cyclic guanosine mono-phosphate-dependent pathways (6). NO has been reported as being central in the pathogenesis of pulmonary hypertension $(7,8)$. A previous study demonstrated that the levels of $\mathrm{NO}$ in lung tissues are lower in patients with $\mathrm{PAH}$, compared wirth healthy controls (9), and that NO inhalation may be effective in pulmonary vasodilator therapy (10). NO synthase (NOS) transforms L-arginine (L-Arg) into NO (11), and the production of NO predominantly depends on the activity of NOS and protein expression.

It has been reported that the oral administration of L-Arg improves the hemodynamics and exercise capacities of patients diagnosed with PAH (12). L-Arg is a common catalyzing substrate of NOS and arginase (Arg), and Arg is the enzyme in the urea cycle, which converts L-Arg into urea and polyamines (13). Thus, Arg and NOS have reciprocal activities that may shift the metabolism of L-Arg towards polyamine homeostasis or twoards NO production, respectively. Arg has two isoforms, Arg I and Arg II. 
Arg I is predominantly expressed in the SMCs, and it has been reported that Arg I contributes to human aortic SMC proliferation (14). The function of Arg in tissues has attracted increasing attention (15).

At present, the function of Arg in the development of PAH remains to be elucidated. The present study aimed to observe the effects of Arg inhibition on PAH and investigate the associated mechanisms. It was hypothesized that Arg inhibition may exert a beneficial role in the prevention and treatment of $\mathrm{PAH}$ and, in order to assess this hypothesis, a series of in vivo and in vitro experiments were designed to investigate the underlying roles and mechanisms. The results may support a novel target for the treatment of PAH.

\section{Materials and methods}

Cell culture. Human pulmonary artery smooth muscle cells (HPASMCs) were purchased from the American Type Culture Collection (Manassas, VA, USA) and were cultured in Dulbecco's modified Eagle's medium containing 10\% fetal bovine serum at $37^{\circ} \mathrm{C}$ in a $5 \% \mathrm{CO}_{2}$ and $95 \%$ air atmosphere. The cells up to the fourth passage were used for the subsequent experiments. The HPASMCs were placed in hypoxic conditions $\left(1 \% \mathrm{O}_{2} ; 5 \% \mathrm{CO}_{2}\right)$ in a cell culture, which was either untreated or pretreated with S-(2-boronoethyl)-L-cysteine (BEC) at $37^{\circ} \mathrm{C}$ for $48 \mathrm{~h}$ (16). BEC (Abcam, Cambridge, UK), an Arg inhibitor, was used as a positive control in the detection of Arg interference.

Measurement of HPASMC proliferation. The proliferation of the HPASMCs was determined using an MTT assay (Beyotime Institute of Biotechnology, Haimen, China). Briefly, the HPASMCs were seeded into 96-well plates at a density of 5,000 cells/well. Following exposure to hypoxic conditions with or without treatment with BEC, the HPASMCs were incubated with $10 \mu \mathrm{l} \mathrm{MTT}(5 \mathrm{mg} / \mathrm{ml}) /$ well for $4 \mathrm{~h}$ at $37^{\circ} \mathrm{C}$. The supernatant was carefully removed and $75 \mu \mathrm{l} /$ well dimethyl sulfoxide was added to dissolve the formazan crystals. The samples were then analyzed at $570 \mathrm{~nm}$ using a Varioskan Flash Multifunction plate reader (Thermo Fisher Scientific, Waltham, MA, USA).

For cell counting, the HPASMCs were seeded in a 6-well plate at the same density as for the MTT assay, and were treated in the above-mentioned conditions. Subsequently, the cells were washed with phosphate-buffered saline, harvested with trypsin and were counted using a hemocytometer (BC-5300; Mindray Medical International Limited, Shenzhen, China).

Rat model of chronic hypoxia exposure. For the in vivo investigations, 8-week-old male Sprague-Dawley rats were exposed to normoxic $\left(21 \% \mathrm{O}_{2}\right)$ or hypoxic $\left(10 \% \mathrm{O}_{2}\right)$ conditions for 3 weeks. During the final 10 days of exposure to the conditions, each animal was administered with either rosiglitazone (10 mg/kg/day; R\&D, Minneapolis, MN, USA) or an equal volume of vehicle (methylcellulose; Fortune Biotech, Shanghai, China) daily by oral gavage. It has been previously reported that this hypoxia regimen stimulates increased right ventricular systolic pressures (RVSP), right ventricular hypertrophy and pulmonary vascular remodeling, and that these hypoxic derangements are attenuated by rosiglitazone (17). All animals had access to standard rat chow and water ad libitum and all procedures were reviewed and approved by the Animal Care and Use Committee of Shandong University (Jinan, China).

Animals. A total of 45 male Sprague-Dawley rats were purchased from the Animal Center of the Shandong University School of Medicine and used for all experiments. All animals were kept under a 12-h light/dark cycle at $25^{\circ} \mathrm{C}$ with five rats per cage. All rats had free access to food and water and were randomly divided into the following three groups, each containing 15 rats: Normal group, control group and Arg group. The rats in the normal group were exposed to normoxic conditions, while the control and Arg groups were exposed to hypoxic or normoxic conditions, and the Arg group was administrated with monocrotaline (Sigma-Aldrich, St. Louis, MO, USA) and the Arg inhibitor, BEC. Subsequent to injection for 24 days, the rats were anesthetized by intraperitoneal injection of $2 \%$ pentobarbital sodium $(0.3 \mathrm{ml} / 100 \mathrm{~g}$; Sigma-Aldrich) and the pulmonary arteries were isolated from the rats of the two groups for the following experiments. All animal care and experimental protocols complied with the animal management rules of the Animal Care and Use Committee of Shandong University (Jinan, China).

Measurement of RVSP. The presence of increased right ventricular pressure confirms the successful establishment of PAH animal models. Prior to sacrification of the rats (by intraperitoneal injection of pentobarbital sodium $(20 \mathrm{mg} / 100 \mathrm{~g}$; Sigma-Aldrich), RVSP was measured by right heart catheterization. The right jugular vein was isolated, following which a small polyethylene catheter was passed through a small transverse cut and advanced into the right ventricle. RVSP was recorded using a miniature pressure transducer digitized by a data acquisition system.

Measurement of Arg activity. The activities of Arg in the HPASMCs and the rats were measured, as previously described (18). Briefly, the cells or tissues were lysed for $30 \mathrm{~min}$ and Tris- $\mathrm{HCl}(25 \mathrm{mM})$ containing $\mathrm{MnCl}_{2}(5 \mathrm{mM}$; $\mathrm{pH}$ 7.4) was added. Arg was activated by heating for $10 \mathrm{~min}$ at $56^{\circ} \mathrm{C}$. The activated lysate was incubated with $0.5 \mathrm{M}$ arginine (pH 9.7) at $37^{\circ} \mathrm{C}$ for $60 \mathrm{~min}$, followed by termination of the reaction. The concentration of urea was measured at $540 \mathrm{~nm}$ using a Varioskan Flash Multifunction reader, with one unit of enzyme activity defined as the quantity of enzyme that catalyzes the formation of $1 \mu \mathrm{mol}$ urea/min.

Reverse transcription-quantitative polymerase chain reaction $(R T-q P C R)$. The pulmonary arteries of the rats were isolated and the HPASMCs were harvested, and the total RNA was extracted using TRIzol reagent (Invitrogen Life Technologies, Carlsbad, CA, USA), according to the manufacturer's instructions. The concentrations of the total RNA were tested using a spectrophotometer. $1 \mu \mathrm{g}$ mRNA was used for reverse transcription in a final volume of $20 \mu 1$. The reverse transcription from mRNA to cDNA was performed using a iScript cDNA synthesis kit (BioRad Laboratories, Inc., Hercules, CA, USA) containing a mixture of oligo(dT) and random primers. Real-time PCR 
was performed with an $\mathrm{iQ}^{\mathrm{TM}}$ SYBR Green Supermix kit (Bio-Rad Laboratories, Inc.) using $1 \mu \mathrm{l}$ cDNA in a $20-\mu 1$ volume. The PCR was performed using an iCycler iQ realtime PCR detection system (Bio-Rad Laboratories, Inc.) and the program was performed for 40 cycles at $95^{\circ} \mathrm{C}$ for $30 \mathrm{sec}$, $55^{\circ} \mathrm{C}$ for $30 \mathrm{sec}$ and $72^{\circ} \mathrm{C}$ for $30 \mathrm{sec}$. In the in vivo experiment, qPCR was performed using the following primers (Biosune, Shanghai, China): Cyclin D1, forward 5'-CAG ACCAGCCTAACAGATTTC-3' and reverse 5'-TGACCC ACAGCAGAAGAAG-3'; cyclin-dependent kinase (CDK)4, forward 5'-GCTACCACTCGATATGAACCCGTGGCT GAA-3' and reverse 5'-GGTGCTTTGTCCAGGTATGTC CGTAGGTCC-3'; p27, forward 5'-CTTGGAGAAGCACTG CCGAGAT-3' and reverse 5'-CCCTGGACACTGCTCCGC TA-3'; and $\beta$-actin, forward 5'-ATCATGTTTGAGACC TTCAACA-3' and reverse 5'-CATCTCTTGCTCGAAGTC CA-3'. In the in vitro experiment, the sequences of primers were as follows: Cyclin D1, forward 5'-CTCCTCTCCGGA GCATTTTGATA-3' and reverse 5'-TTAAAGACAGTTTTT GGGTAATCT-3'; CDK4, forward 5'-ATGGCTACCTCT CGATATGAGCCA-3' and reverse 5'-TCACTCCGGATT ACCTTCATCCTT-3'; and p27, forward 5'-CTTGGAGAA GCACTGCCGAGAT-3' and reverse 5'-CCCTGGACACTG CTCCGCTA-3'. The relative expression levels of the genes was obtained using the $2^{-\Delta \Delta \text { ct }}$ calculation method (19). Each sample was analyzed in triplicate and the expression levels were normalized to that of $\beta$-actin.

Western blot analysis. The total proteins were extracted from pulmonary arteries of the rats and HPASMCs. HPASMCs were scraped off the dish, and the cell suspension was transferred into a pre-cooled tube. $30 \mathrm{mg}$ pulmonary arteries of the rats were dissected and placed in $300-\mu 1$ cooled lysis buffer. Lysates were kept on ice for immediate homogenization and maintained under constant agitation for $30 \mathrm{~min}$ at $4^{\circ} \mathrm{C}$. The mixtures were centrifuged for $20 \mathrm{~min}$ at $16,000 \mathrm{xg}$ at $4^{\circ} \mathrm{C}$. The protein lysate was then transferred to a fresh tube on ice and an equal volume of $2 \mathrm{X}$ loading buffer was added. Each lysate was boiled in loading buffer at $99^{\circ} \mathrm{C}$ for $5 \mathrm{~min}$ and subsequently stored at $-20^{\circ} \mathrm{C}$ for western blotting. The protein concentrations were assayed using a bicinchoninic acid method (Beyotime Institute of Biotechnology, Haimen, China). The samples were separated on a 10-12\% SDS-polyacrylamide gel and electrophoretically transferred onto a nitrocellulose membrane (EMD Millipore, Billerica, MA, USA). Following blocking with $5 \%$ non-fat milk for $2 \mathrm{~h}$ at room temperature, the membrane was washed in Tris-buffered saline with Tween 20 (TBS-T; Beyotime Institute of Biotechnology) three times for $10 \mathrm{~min}$. Subsequently, the membrane was incubated with primary antibodies, including rabbit polyclonal cyclin D1 antibody (1:1,000; Cell Signaling Technology, Inc., Danvers, MA, USA), rabbit polyclonal CDK4 (1:500; Abcam, Cambridge, MA, USA), rabbit monoclonal anti-p27 (1:500; Abcam), rabbit monoclonal anti-Akt and monoclonal phosphorylated (p)-Akt (1:1,000; Cell Signaling Technology, Inc.), rabbit monoclonal anti-ERK and monoclonal p-ERK (1:1,000; Cell Signaling Technology, Inc.) and rabbit monoclonal anti- $\beta$-actin $(1: 1,000$; Cell Signaling Technology, Inc.) antibodies at $4^{\circ} \mathrm{C}$ overnight. Following washing with TBS-T three times, the membrane
A

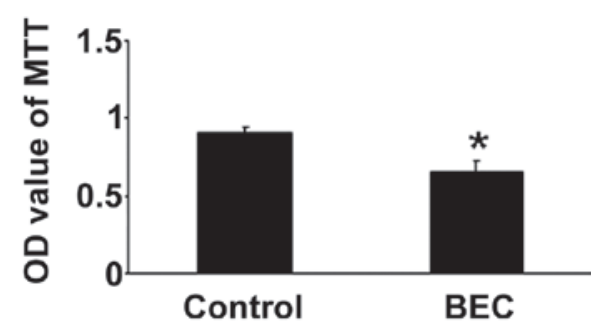

B

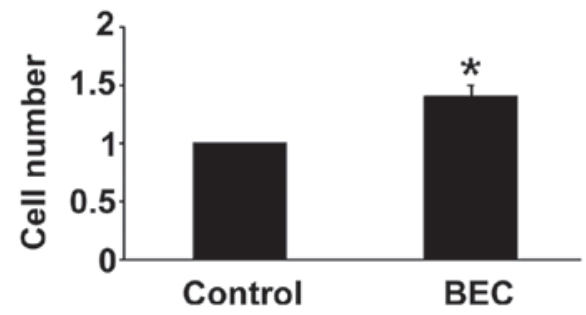

Figure 1. Arg inhibition reduces the proliferation of HPASMCs induced by hypoxia. HPASMC proliferation was assessed using an (A) MTT assay and via (B) cell counting. Data are expressed as the mean \pm standard error of the mean. ${ }^{*} \mathrm{P}<0.05$, vs. control; HPASMCs, human pulmonary artery smooth muscle cells; BEC, Arg inhibitor; OD, optical density.

was incubated with a horseradish peroxidase-conjugated secondary antibody. The bands were detected using an enhanced chemiluminescent method (EMD Millipore) and analyzed using Image-Pro Plus software, version 6.0 (Media Cybernetics, Inc., Rockville, MD, USA).

Statistical analyses. Analysis of the data was performed using SPSS, version 13.0 (SPSS, Inc., Chicago, IL, USA). Continuous variables are expressed as the mean \pm standard error of the mean. All statistical comparisons were performed using Student's t-test or one-way analysis of variance. $\mathrm{P}<0.05$ was considered to indicate a statistically significant difference.

\section{Results}

BEC reduces hypoxia-induced HPASMC proliferation in vitro. The effects of BEC on HPASMC proliferation were evaluated under hypoxic conditions. The MTT assay demonstrated that the inhibition of Arg by BEC inhibited HPASMC proliferation, compared with the hypoxia group. The cell counting assay produced similar results $(\mathrm{P}<0.05$; Fig. 1$)$. The regulation of Arg inhibition on HPASMC proliferation may be one important mechanism of anti-PAH.

Arg inhibition arrests HPASMCs in the $G_{1} / G_{0}$-phase under hypoxic conditions. The proliferation of cells is dependent on the cell cycle transition between the $G_{1} / G_{0}$ and the $G_{2} / S$ phases. In the present study, whether the Arg inhibitor affected the cell cycle distribution of HPASMCs was investigated. As shown in Fig. 2A, compared with the control group, BEC treatment arrested a higher percentage of HPASMCs in the $G_{1} / G_{0}$ phase $(\mathrm{P}<0.05)$.

Arg inhibition reduces the expression levels of cyclin D1 and $C D K 4$, and increases the expression of p27. The mechanism underlying the effect of hypoxia was then investigated. 
A

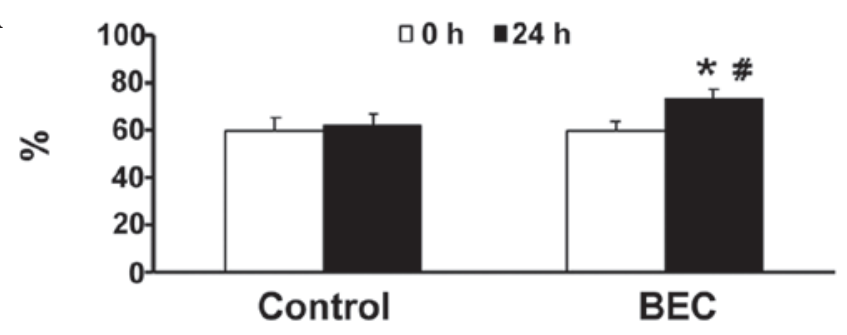

C

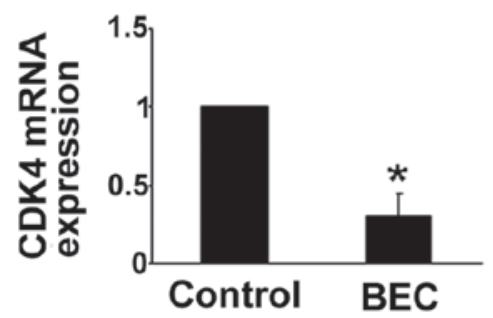

F

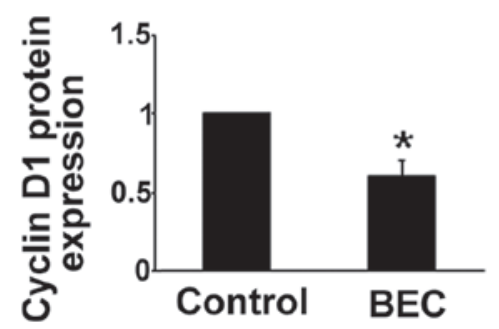

D

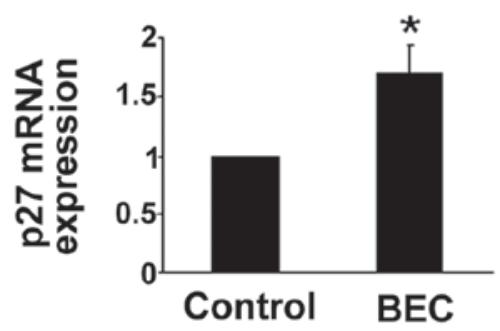

G

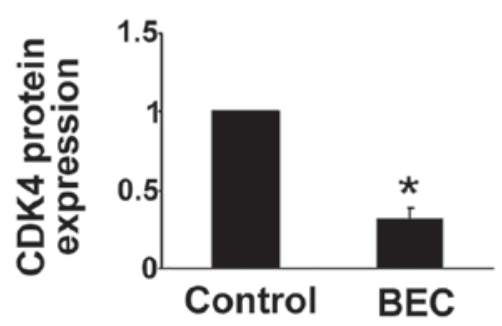

B

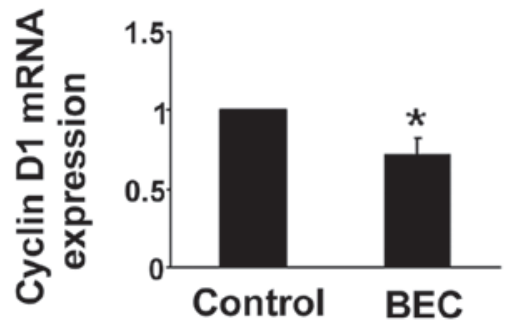

E

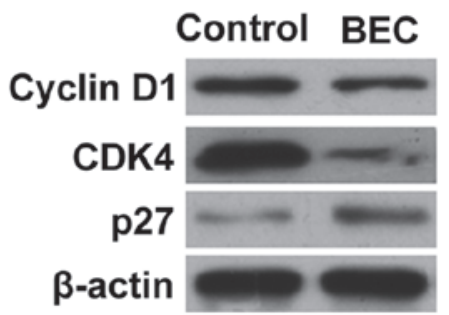

H

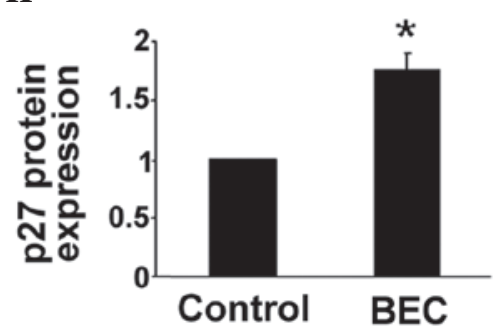

Figure 2. Arg inhibition arrests HPASMCs in the $\mathrm{G}_{1} / \mathrm{G}_{0}$-phase under hypoxic conditions in vitro. (A) Cell cycle of HPASMCs. mRNA expression levels of (B) cyclin D1, (C) CDK4 and (D) p27 was assessed using reverse transcription-quantitative polymerase chain reaction. Protein expression levels of (E-H) cyclin D1, CDK4 and p27 were assessed using western blot analysis. Data are expressed as the mean \pm standard error of the mean. * $<0.05$, vs. control. HPASMCs, human pulmonary artery smooth muscle cells; CDK, cyclin-dependent kinase; BEC, S-(2-boronoethyl)-L-cysteine.

Previous studies have demonstrated that cyclin D1, CDK4 and $\mathrm{p} 27$ are key in regulation of cell proliferation and the cell cycle, therefore, the effects of hypoxia and BEC on their levels of expression were evaluated in the HPASMCs. RT-qPCR analysis revealed that the gene expression levels of cyclin D1 and CDK4 were significantly reduced in the Arg inhibitor group, compared with those in the control group, whereas treatment with the Arg inhibitor treatment significantly enhanced hypoxia-induced gene expression of p27 ( $<<0.05$; Fig. 2B-D). Similar results were obtained in the western blot analyses $(\mathrm{P}<0.05$; Fig. $2 \mathrm{E}-\mathrm{H})$.

The levels of cyclin D1, CDK4 and p27 were measured in vivo in the pulmonary arteries of the rats. As hypothesized, compared with the control group, the gene and protein expression levels of cyclin D1 and CDK4 were markedly reduced, and the expression of p27 was markedly increased in the BEC-treated rats $(\mathrm{P}<0.0$; Fig. 3). These results indicated that the regulation of Arg inhibition on the cell cycle may be another mechanism of its anti-PAH effects.

Arg inhibition decreases the phosphorylation of Akt and $E R K 1 / 2$. It has been reported that the Akt and ERK pathways are involved in the proliferation pfHPASMCs and progression of PAH (20). Thus, in the present study, the protein expression levels of Akt and ERK in vitro were assessed using western blot analysis. Compared with the hypoxia group, Arg inhibition downregulated the phosphorylation of Akt and ERK, which may be another mechanism of the protective effects of Arg inhibition $(\mathrm{P}<0.05$; Fig. 4).

Arg inhibition reduces the PAH-induced increase of RVSP. The hemodynamic parameters of rats were measured prior to sacrifice. No significant differences were observed in the mean blood pressure or heart rate among the groups (data not shown). Compared with the control group, the rats in the PAH group exhibited a higher RVSP. However, following the inhibition of Arg with BEC, the RVSP was significantly reduced $(\mathrm{P}<0.05$; Fig. 5). These results suggested that Arg inhibition reduced the PAH-induced increase of RVSP.

Hypoxia increases the activity of Arg in vivo. The activity of Arg in vivo was also assessed, as previously described (18). The results demonstrated that, compared with the control group, hypoxia significantly increased the activity of Arg, and this was reduced following Arg inhibition by BEC (Fig. 5).

\section{Discussion}

PAH is a life-threatening disease, the etiology of which remains to be elucidated. Although a number of studies have focused on the development and treatment of $\mathrm{PAH}$, few effective therapies have been developed. The most important finding of the present study was that Arg inhibition prevented the progression of PAH in the rat model. 


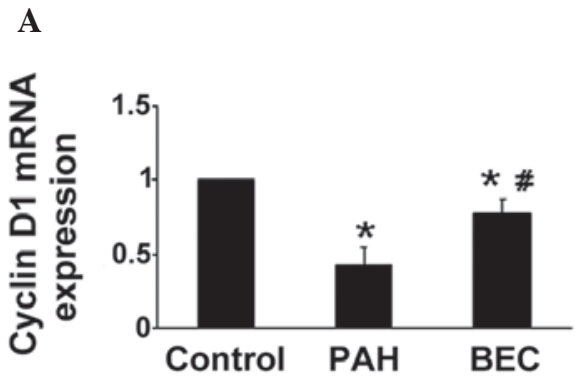

B

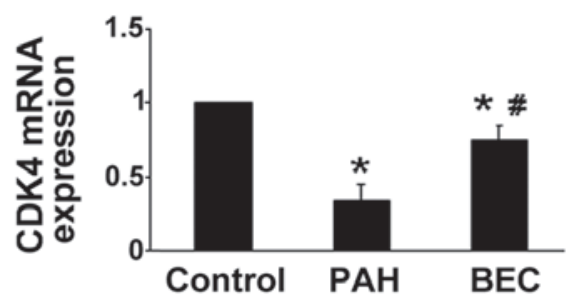

C
D

\section{Control PAH BEC}

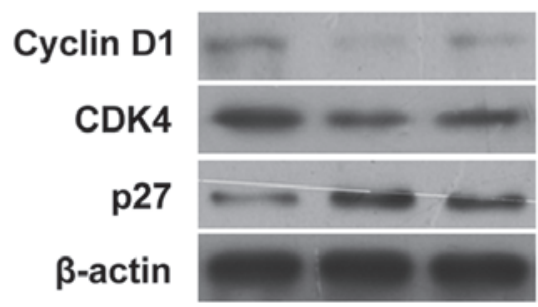

F

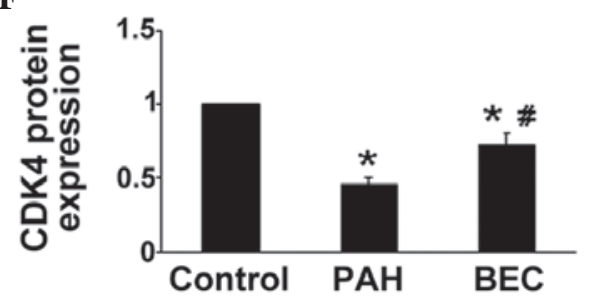

$\mathbf{E}$

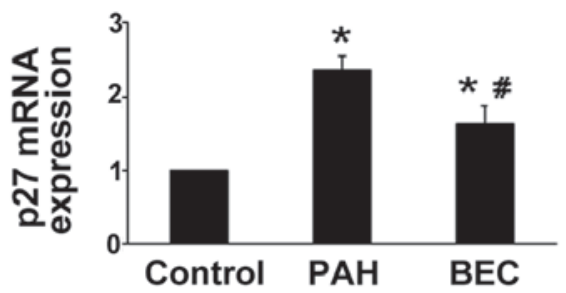

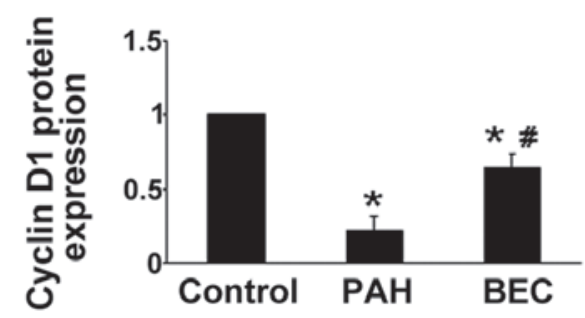

G

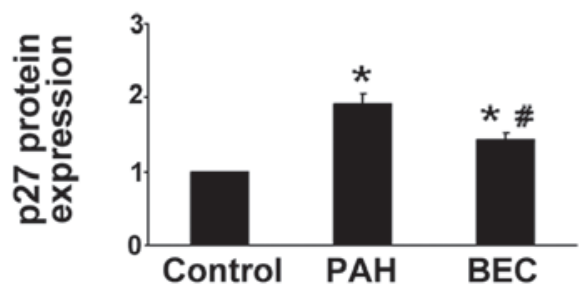

Figure 3. Arg inhibition regulates the expression levels of cyclin D1, CDK4 and p27 in vivo. The mRNA expression levels of (A) cyclin D1, (B) CDK4 and (C) p27 were assessed using reverse transcription-quantitative polymerase chain reaction. (D) Protein expression levels of (E) cyclin D1, (F) CDK4 and (G) p27 were assessed using western blot analysis. Data are expressed as the mean \pm standard error of the mean.. $\mathrm{P}<0.05$, vs. control; ${ }^{\#} \mathrm{P}<0.05$, vs. $\mathrm{CDK}$, cyclin-dependent kinase; PAH, rats with pulmonary arterial hypertension; BEC, S-(2-boronoethyl)-L-cysteine-treated rats.

A

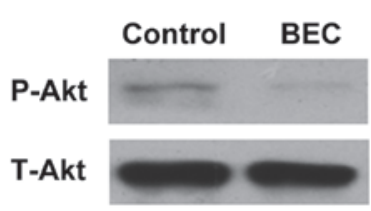

B

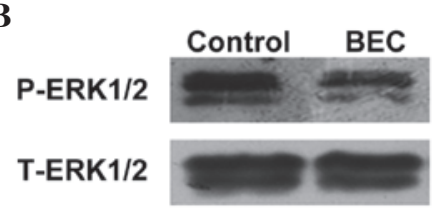

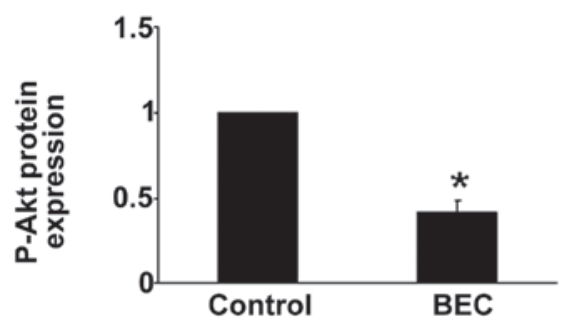

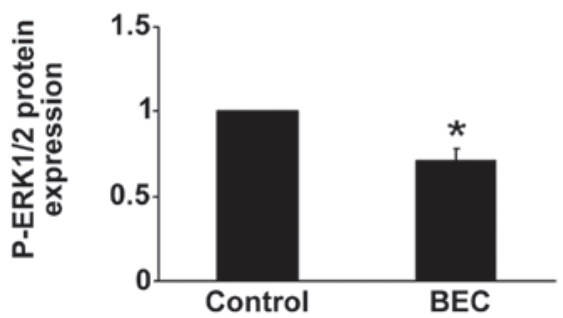

Figure 4. Arg inhibition reduced the phosphorylation of Akt and ERK in vitro. (A) The phosphorylation of Akt was assayed by western blot analysis. (B) The phosphorylation of ERK was assayed by western blot analysis. "P<0.05, vs. control. Akt, protein kinase B; ERK, extracellular signal-related kinase; p-, phosphorylated; t-, total; BEC, S-(2-boronoethyl)-L-cysteine.

The major mechanisms may involve significant inhibition of HPASMC proliferation, regulation of the cell cycle and reduced expression levels of Akt and ERK by BEC. To the best of our knowledge, this is a novel observation regarding the Arg inhibitor BEC.
Increased pulmonary artery constriction and remodeling is a key characteristic of PAH. NO, synthesized by NOS, is considered to be critical in maintaining pulmonary arterial pressure and vascular resistance, and it has been reported that NO is involved in the pathogenesis of pulmonary 
A

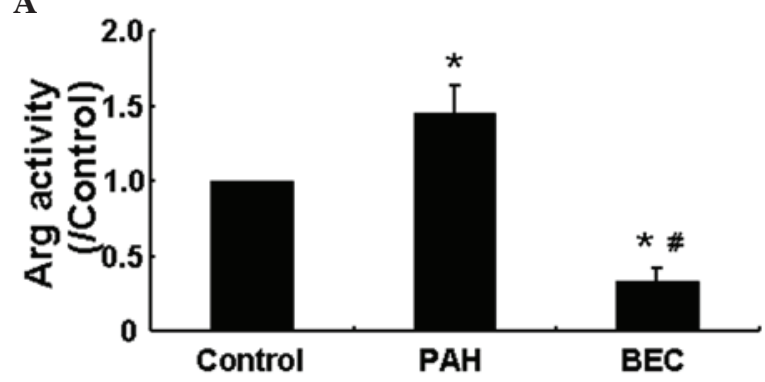

B

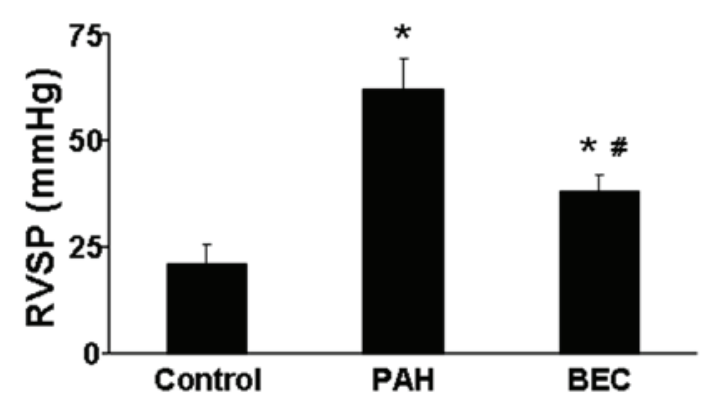

Figure 5. Arg inhibition reduces the increase in RVSP in rats. (A) Activity of Arg in the three groups; (B) levels of RVSP in the three groups. Data are expressed as the mean \pm standard error of the mean. $\mathrm{P}<0.05$, vs. control; ${ }^{\#} \mathrm{P}<0.05$, vs. PAH. RVSP, right ventricle systolic pressure; PAH, rats with pulmonary arterial hypertension; BEC, S-(2-boronoethyl)-L-cysteine-treated rats.

hypertension (21). A reduction in NO promotes the development of pulmonary hypertension (22). It was reported previously that, in an animal model of NOS-deficient mice, increased mean pulmonary arterial pressure was observed, and pulmonary arterial pressure was partially restored following the transfer of NOS to the mice (23). NO inhalation has been considered as an effective method in $\mathrm{PAH}$ therapy (10). L-Arg is a common catalyzing substrate of NOS and Arg, and the metabolic pathway of L-Arg is an important mechanism of NO synthesis, where the presence of L-Arg augments NO synthesis and endothelium-dependent vasodilation. However, Arg has been reported to compete with NOS for the common catalyzing substrate, thus shifting the metabolism of arginine to urea (19). Therefore, inhibition of Arg may inhibit the conversion of L-Arg to urea and increase NO synthesis.

The principal phenotype of SMCs is contraction, which preserves vasodilation and blood flow regulation in physiological conditions. However, SMCs exhibit a 'synthetic' phenotype in pathological conditions, and increase the capacity of proliferation and generation of matrix components of the blood vessel wall, contributing to vascular remodeling (24). Aberrant HPASMC proliferation leads to pulmonary arterial remodeling and contributes to the progression of $\mathrm{PAH}$, whereas effective inhibition the aberrant HPASMCs can delay and even halt the deteriorative progression of PAH (4). In the present study, the role of Arg inhibition in the proliferation of hypoxia-induced HPASMCs was investigated, which revealed that Arg inhibition effectively inhibited the proliferation of HPASMCs. Therefore, the anti-PAH properties of Arg inhibition in the rats may have been attributed to its role in HPASMCs proliferation.

Under hypoxic conditions, more HPASMCs enter cell mitosis, and acceleration of the cell cycle is an initial factor in cell proliferation. Hypoxia has been reported to result in low cell numbers in the $\mathrm{G}_{0} / \mathrm{G}_{1}$ phase and an increase in HPASMCs entering $G_{2} / S$ phase (25). In the present study, the effects of Arg inhibition on the cell cycle of HPASMCs were assessed, and it was demonstrated that Arg inhibition reversed the effect of hypoxia.

A previous study reported that the balance between cell quiescence and proliferation is regulated by cyclin-dependent kinases (CDKs) and CDK inhibitors (26). Cyclin D1 and CDKs, predominantly CDK4, are key genes controlling the cell cycle, are associated with cell proliferation and facilitate the transition of cells between the $G_{1}$ phase and the $\mathrm{S}$ phase (27). The overexpression of CDK4 promotes cell proliferation, whereas inhibition of the expression of CDK4 can lead to arrest at the $G_{1}$ phase and the suppression of cell proliferation (28). In the present study, Arg inhibition significantly reduced the expression levels of cyclin D1 and CDK4 in vivo and in vitro. $\mathrm{p} 27$, as one of the key CDK inhibitors, effectively inhibits cyclin D1-CDK4 protein kinase activity and negatively regulates $\mathrm{G}_{1}$ progression in cells, and verexpression of p27 results in $\mathrm{G}_{1}$ arrest and reduces the proliferation of HPASMCs (29). The results of the present study demonstrated that Arg inhibition increased the mRNA and protein expression levels of p27 in vivo and in vitro. Thus, it was suggested that Arg inhibition promoted $\mathrm{G}_{1}$ phase arrest, which may be the direct mechanism of Arg inhibition against HPASMCs proliferation and PAH.

The activation of Akt and ERK by diverse extracellular signals triggers cellular cascade responses, including cell growth, proliferation, survival and motility, prompting investigation of their expression in the present study. The levels of p-Akt and p-ERK were higher in the hypoxic HPASMCs, compared with the control cells, and Arg inhibition inhibited the activation of the Akt and ERK pathways.

The findings of the present study provide support for inhibition of Arg as a useful therapeutic intervention for the treatment of pulmonary hypertensive disorders.

\section{References}

1. Frumkin LR. The pharmacological treatment of pulmonary arterial hypertension. Pharmacol Rev 64: 583-620, 2012.

2. Humbert M, Morrell NW, Archer SL, Stenmark KR, MacLean MR, Lang IM, Christman BW, Weir EK, Eickelberg O and Voelkel NF: Cellular and molecular pathobiology of pulmonary arterial hypertension. J Am Coll Cardiol 43 (Suppl 12): 13S-24S, 2004.

3. Orlandi A, Bochaton-Piallat ML, Gabbiani G and Spagnoli LG: Aging, smooth muscle cells and vascular pathobiology: Implications for atherosclerosis. Atherosclerosis 188: 221-230, 2006.

4. Luo Y, Xu DQ, Dong HY, Zhang B, Liu Y, Niu W, Dong MQ and Li ZC: Tanshinone iia inhibits hypoxia-induced pulmonary artery smooth muscle cell proliferation via Akt/Skp2/p27-associated pathway. PLoS One 8: e56774, 2013.

5. Stenmark KR, Fagan KA and Frid MG: Hypoxia-induced pulmonary vascular remodeling: Cellular and molecular mechanisms. Circ Res 99: 675-691, 2006.

6. Vasa M, Fichtlscherer S, Adler K, Aicher A, Martin H, Zeiher AM and Dimmeler S: Increase in circulating endothelial progenitor cells by statin therapy in patients with stable coronary artery disease. Circulation 103: 2885-2890, 2001. 
7. Sudar E, Dobutovic B, Soskic S, Mandusic V, Zakula Z, Misirkic M, Vucicevic L, Janjetovic K, Trajkovic V, Mikhailidis DP, et al: Regulation of inducible nitric oxide synthase activity/expression in rat hearts from ghrelin-treated rats. J Physiol Biochem 67: 195-204, 2011.

8. Isenovic ER, Meng Y, Divald A, Milivojevic N and Sowers JR: Role of phosphatidylinositol 3-kinase/akt pathway in angiotensin ii and insulin-like growth factor-1 modulation of nitric oxide synthase in vascular smooth muscle cells. Endocrine 19: 287-292, 2002.

9. Kaneko FT, Arroliga AC, Dweik RA, Comhair SA, Laskowski D, Oppedisano R, Thomassen MJ and Erzurum SC: Biochemical reaction products of nitric oxide as quantitative markers of primary pulmonary hypertension. Am J Respir Crit Care Med 158: 917-923, 1998

10. Pepke-Zaba J, Higenbottam TW, Dinh-Xuan AT, Stone D and Wallwork J: Inhaled nitric oxide as a cause of selective pulmonary vasodilatation in pulmonary hypertension. Lancet 338: 1173-1174, 1991.

11. Ribeiro MO, Antunes E, de Nucci G, Lovisolo SM and Zatz R: Chronic inhibition of nitric oxide synthesis. A new model of arterial hypertension. Hypertension 20: 298-303, 1992.

12. Nagaya N, Uematsu M, Oya H, Sato N, Sakamaki F, Kyotani S, Ueno K, Nakanishi N, Yamagishi M and Miyatake K: Short-term oral administration of 1-arginine improves hemodynamics and exercise capacity in patients with precapillary pulmonary hypertension. Am J Respir Crit Care Med 163: 887-891, 2001.

13. Mori $\mathrm{M}$ and Gotoh T: Regulation of nitric oxide production by arginine metabolic enzymes. Biochem Biophys Res Commun 275: 715-719, 2000.

14. Wei LH, Wu G, Morris SM Jr and Ignarro LJ: Elevated arginase I expression in rat aortic smooth muscle cells increases cell proliferation. Proc Natl Acad Sci USA 98: 9260-9264, 2001.

15. Ckless K, Lampert A, Reiss J, Kasahara D, Poynter ME, Irvin CG, Lundblad LK, Norton R, van der Vliet A and Janssen-Heininger YM: Inhibition of arginase activity enhances inflammation in mice with allergic airway disease, in association with increases in protein s-nitrosylation and tyrosine nitration. J Immunol 181: 4255-4264, 2008.

16. Lu X, Murphy TC, Nanes MS and Hart CM: Ppar\{gamma\} regulates hypoxia-induced nox4 expression in human pulmonary artery smooth muscle cells through nf-\{kappa B. Am J Physiol Lung Cell Mol Physiol 299: L559-L566, 2010

17. Crossno JT Jr, Garat CV, Reusch JE, Morris KG, Dempsey EC, McMurtry IF, Stenmark KR and Klemm DJ: Rosiglitazone attenuates hypoxia-induced pulmonary arterial remodeling. Am J Physiol Lung Cell Mol Physiol 292: L885-L897, 2007.
18. Corraliza IM, Campo ML, Soler G and Modolell M: Determination of arginase activity in macrophages: A micromethod. J Immunol Methods 174: 231-235, 1994.

19. Wang XP, Chen YG, Qin WD, Zhang W, Wei SJ, Wang J, Liu FQ, Gong L, An FS and Zhang Y: Arginase i attenuates inflammatory cytokine secretion induced by lipopolysaccharide in vascular smooth muscle cells. Arterioscler Thromb Vasc Biol 31: 1853-1860, 2011.

20. Kiss T, Kovacs K, Komocsi A, Tornyos A, Zalan P, Sumegi B, Gallyas F Jr and Kovacs K: Novel mechanisms of sildenafil in pulmonary hypertension involving cytokines/chemokines, MAP kinases and Akt. PLoS One 9: e104890, 2014.

21. Xu W, Kaneko FT, Zheng S, Comhair SA, Janocha AJ, Goggans T, Thunnissen FB, Farver C, Hazen SL and Jennings C: Increased arginase ii and decreased no synthesis in endothelial cells of patients with pulmonary arterial hypertension. FASEB J 18: 1746-1748, 2004 .

22. Fagan KA, Morrissey B, Fouty BW, Sato K, Harral JW, Morris KG Jr, Hoedt-Miller M, Vidmar S, McMurtry IF and Rodman DM: Upregulation of nitric oxide synthase in mice with severe hypoxia-induced pulmonary hypertension. Respir Res 2: 306-313, 2001.

23. Champion HC, Bivalacqua TJ, Greenberg SS, Giles TD, Hyman AL and Kadowitz PJ: Adenoviral gene transfer of endothelial nitric-oxide synthase (enos) partially restores normal pulmonary arterial pressure in enos-deficient mice. Proc Natl Acad Sci USA 99: 13248-13253, 2002.

24. Owens GK: Regulation of differentiation of vascular smooth muscle cells. Physiol Rev 75: 487-517, 1995.

25. Kadowaki M, Mizuno S, Demura Y, Ameshima S, Miyamori I and Ishizaki T: Effect of hypoxia and Beraprost sodium on human pulmonary arterial smooth muscle cell proliferation: the role of p27kip1. Respir Res 8: 77, 2007.

26. Yu L, Quinn DA, Garg HG and Hales CA: Gene expression of cyclin-dependent kinase inhibitors and effect of heparin on their expression in mice with hypoxia-induced pulmonary hypertension. Biochem Biophys Res Commun 345: 1565-1572, 2006.

27. Dong Y, Sui L, Sugimoto K, Tai Y and Tokuda M: Cyclin D1-cdk4 complex, a possible critical factor for cell proliferation and prognosis in laryngeal squamous cell carcinomas. Int J Cancer 95: 209-215, 2001.

28. Sakamoto K, Ohki K, Saito M, Nakahara T and Ishii K: Small molecule cyclin-dependent kinase inhibitors protect against neuronal cell death in the ischemic-reperfused rat retina. J Ocul Pharmacol Ther 27: 419-425, 2011.

29. Toyoshima $\mathrm{H}$ and Hunter T: P27, a novel inhibitor of g1 cyclin-cdk protein kinase activity, is related to p21. Cell 78: 67-74, 1994. 